\title{
Circuit Investigation of Social Interaction and Substance Use Disorder Using Miniscopes
}

\author{
Nicholas J. Beacher ${ }^{1 *}$, Kayden A. Washington ${ }^{1}$, Craig T. Werner ${ }^{1,2}$, Yan Zhang ${ }^{1}$, \\ Giovanni Barbera', Yun Li ${ }^{3}$ and Da-Ting Lin ${ }^{1}$ \\ 1 Intramural Research Program, National Institute on Drug Abuse, National Institutes of Health, Baltimore, MD, United States, \\ ${ }^{2}$ Department of Pharmacology and Physiology, Oklahoma State University Center for Health Sciences, Tulsa, OK, \\ United States, ${ }^{3}$ Department of Zoology and Physiology, University of Wyoming, Laramie, WY, United States
}

OPEN ACCESS

Edited by:

$\operatorname{Han} X u$,

Zhejiang University, China

Reviewed by:

Tycho Hoogland,

Erasmus Medical Center, Netherlands

Chaoran Ren,

Jinan University, China

*Correspondence:

Nicholas J. Beacher

Nicholas.beacher@nih.gov

Received: 21 August 2021 Accepted: 16 September 2021

Published: 05 October 2021

Citation:

Beacher NJ, Washington KA, Werner CT, Zhang Y, Barbera G, Li Y

and Lin D-T (2021) Circuit

Investigation of Social Interaction and Substance Use Disorder Using

Miniscopes.

Front. Neural Circuits 15:762441. doi: 10.3389/fncir.2021.762441
Substance use disorder (SUD) is comorbid with devastating health issues, social withdrawal, and isolation. Successful clinical treatments for SUD have used social interventions. Neurons can encode drug cues, and drug cues can trigger relapse. It is important to study how the activity in circuits and embedded cell types that encode drug cues develop in SUD. Exploring shared neurobiology between social interaction (SI) and SUD may explain why humans with access to social treatments still experience relapse. However, circuitry remains poorly characterized due to technical challenges in studying the complicated nature of SI and SUD. To understand the neural correlates of SI and SUD, it is important to: (1) identify cell types and circuits associated with SI and SUD, (2) record and manipulate neural activity encoding drug and social rewards over time, (3) monitor unrestrained animal behavior that allows reliable drug self-administration (SA) and SI. Miniaturized fluorescence microscopes (miniscopes) are ideally suited to meet these requirements. They can be used with gradient index (GRIN) lenses to image from deep brain structures implicated in SUD. Miniscopes can be combined with genetically encoded reporters to extract cell-type specific information. In this minireview, we explore how miniscopes can be leveraged to uncover neural components of SI and SUD and advance potential therapeutic interventions.

Keywords: miniature fluorescence microscopy, miniscope, in vivo calcium imaging, longitudinal imaging, substance use disorder, social interaction

\section{INTRODUCTION}

Communicating or being around others, Social Interaction (SI), is crucial for health and wellness in humans (Hunt and Azrin, 1973; Kawachi and Berkman, 2001; Dishion and Stormshak, 2007), and animals (Council, 2010). People suffering from substance use disorder (SUD) oftentimes selfisolate from friends and family (Young A.M. et al., 2001), but fortunately, social interventions and group therapies promote drug abstinence (Hunt and Azrin, 1973). In preclinical models, animals self-administer (SA) SI over drugs of abuse in "choice" tasks (Venniro et al., 2019; Venniro and Shaham, 2020). However, people in recovery from SUD still experience relapse despite access to therapy (Nestler, 2002). 
Similar reward-related brain areas underlie SI and SUD (Peoples and West, 1996; Young L.J. et al., 2001; Tang et al., 2005; Bergan et al., 2014; Holder et al., 2015; Manduca et al., 2016). It is critical to study the neurobiology underlying the therapeutic potential of SI in the treatment of SUD. First, it is important understand cell types and genetic information for potential molecular contributions to SI and SUD. Second, neurons can encode cues that are associated with drug rewards (Robinson and Berridge, 1993; Flagel et al., 2008) and drug craving and relapse can be triggered by drug cues in humans with SUD (Kennedy et al., 2013). Therefore, it is of great importance to monitor how neurons encode drug and social reward cues over extended periods of time and then directly manipulate them to determine their function. This need for in vivo observation of neural activity necessitates creating conditions to monitor unrestrained animal behavior that allows reliable drug SA and SI. However, circuitry underlying SI and SUD remains poorly characterized due to technical challenges and the complicated (and intertwined) nature of SI and SUD. Miniaturized fluorescence microscopes (miniscopes) are ideally suited to meet the outlined requirements Miniscopes in combination with gradient index (GRIN) lenses can record neurons in deep brain structures implicated in SI and SUD, and can be combined with optogenetic tools to manipulate neuronal activity and genetically encoded reporters to extract genetic and cell-type specific information.

The miniscope's compact nature allows for the study of complex behaviors, such as SI and drug SA, in freely moving animals. In this mini-review we first discuss the genetic and hardware technologies that helped make the miniscope GRIN lens system ideal for working with in vivo animal models. We then explore how miniscopes can be leveraged to uncover the neurobiological components of SI and SUD in order to advance potential therapeutic interventions of SI for SUD.

\section{PARALLEL ADVANCES IN CALCIUM IMAGING AND MINISCOPE DEVELOPMENT}

Calcium indicators have evolved from chemical dyes to genetically encoded proteins to provide insight on in vivo neural activity (Rose et al., 2014). Genetically encoded calcium indicators (GECIs) have allowed cell-specific targeting of neurons to measure transient increases in $\mathrm{Ca}^{2+}$ associated with neuronal spiking (Tian et al., 2009; Chen et al., 2013; Gerfen et al., 2013; Rose et al., 2014; Zhang et al., 2020). Active neurons fire action potentials and result in transient increases in intracellular $\mathrm{Ca}^{2+}$ which upon binding to a GECI can increase its fluorescence intensity (Nakai et al., 2001; Tallini et al., 2006; Akerboom et al., 2012; Förster et al., 2018; Yang et al., 2018). Therefore, individual neuronal activity can be readily monitored through fluorescence changes of the GECI. In addition, the development of head mounted widefield miniaturized fluorescence microscopes (miniscopes) paired with Gradient Index (GRIN) lens implantation, enables deep brain in vivo $\mathrm{Ca}^{2+}$ imaging and analysis of neural mechanisms in awake and freely behaving animals (Ghosh et al., 2011;
Markowitz et al., 2015; Barbera et al., 2016, 2019; Cai et al., 2016; Okuyama et al., 2016; Klaus et al., 2017; Chen et al., 2018; Jimenez et al., 2018; Liang et al., 2018; Werner et al., 2019; Zhang et al., 2019; de Groot et al., 2020; Shuman et al., 2020; Figure 1).

Through the implanted GRIN lens, fluorescent signals emitted by neurons are collected by the miniscope (Leiner and Prescott, 1983; Levene et al., 2004; Zhang et al., 2019; Laing et al., 2021). This miniscope and GRIN lens system allows for exploring a variety of aspects of neural activity from individual neurons and neural ensembles (Bollimunta et al., 2021). Some of these aspects include identifying neuronal subtypes and observing microcircuits that encode behavior. The identified circuits can then be manipulated through optogenetics to determine function (Kondabolu et al., 2015; Martín et al., 2015; Barbera et al., 2016; Heinsbroek et al., 2017; Natsubori et al., 2017; Parker et al., 2018).

Recent advances have been made to the miniscope procedure, such as biologically safe coating on the GRIN lens (Kyogoku et al., 1990; Yang et al., 2019) which would otherwise leak toxic compounds and cause neurodegeneration near the site of the lens implantation (Table 1). Higher precision surgical tools have also allowed for a greater level of sustainability and survivability post-surgery (Liang et al., 2019). With decreased lens toxicity and reduced surgically induced inflammation researchers can follow the activity of neurons over time using miniscopes and image healthier tissue. Furthermore, increased animal mobility during miniscope imaging has been achieved with the advent of motorized commutators (Coward and O'Boyle, 1979; Fee and Leonardo, 2001; Barbera et al., 2020) and wire-free miniscopes (Barbera et al., 2019; Shuman et al., 2020; Table 1). The advent of deep learning algorithms to track animal behavior has helped better align neural activity with behavior in individual and groups of animals, which is important for the study of SI and SUD. For example, behavior can be analyzed using deep learning software (Hong et al., 2015; Mathis et al., 2018; Mosser et al., 2021) such as DeepLabCut (Mathis et al., 2018; Nath et al., 2019; Table 1). Dual color miniscopes can record from two cell types simultaneously within the same animal, which provides a powerful tool to uncover spatiotemporal dynamics of activity in multiple cell subpopulations that are active during SI and in SUD (Jacob et al., 2018; Leman et al., 2018; Figure 1). An Electrowetting Lens (Kuiper and Hendriks, 2004; Ren and Wu, 2007) is able to remotely adjust focus between neurons across different focal planes and can also be incorporated into miniscopes (Hayashi et al., 2021; Figure 1). In combination these advancements have greatly facilitated uncovering the spatiotemporal dynamics of neural activity during behavior.

\section{BENEFITS OF USING MINISCOPES IN ANIMAL MODELS}

\section{Identifying Genetic Components and/or Specific Cell Subtypes}

The first step in dissecting the underlying neurobiological contributions associated with SI and SUD is to determine the exact types of cells that are being recorded. For example, the 


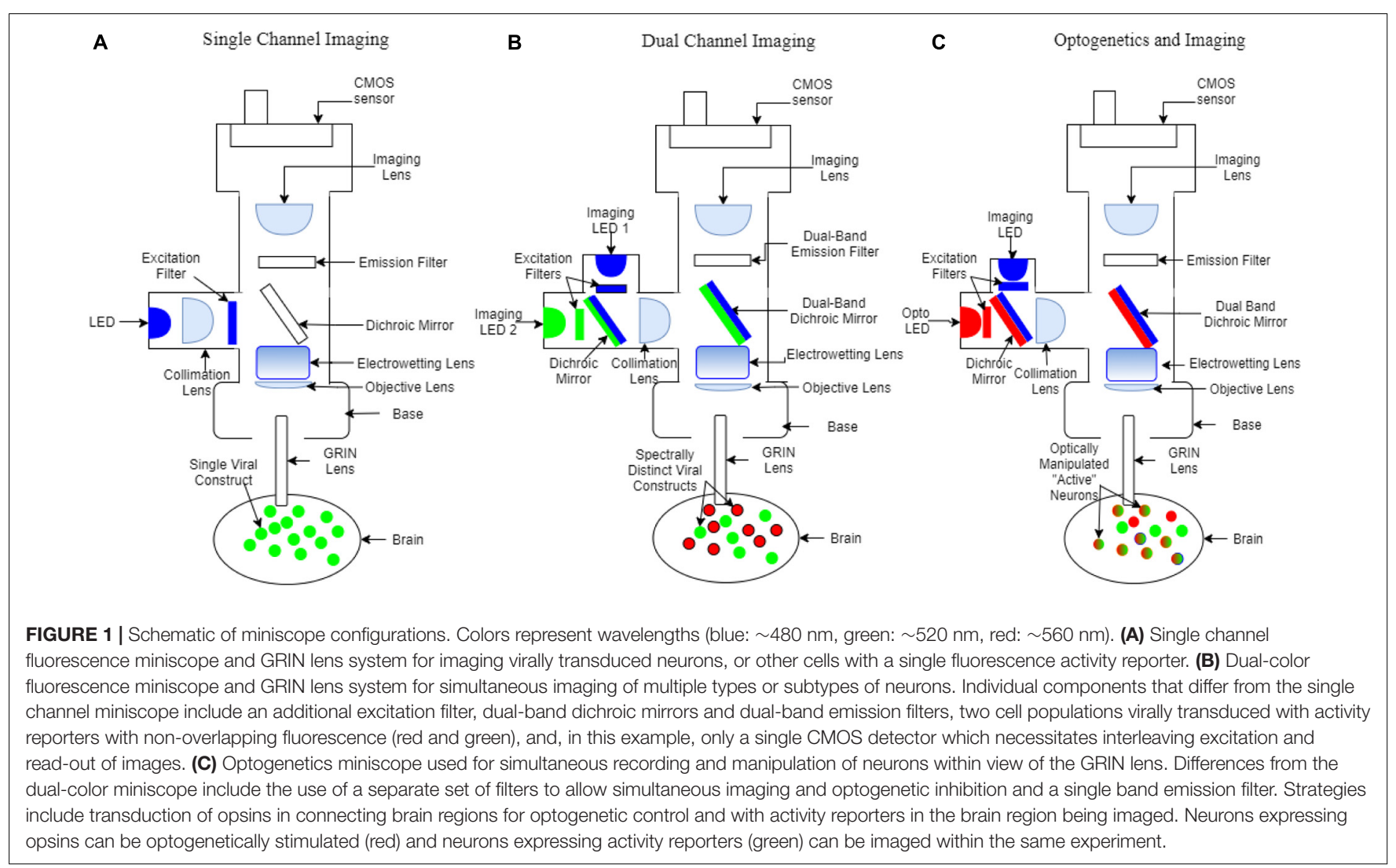

nucleus accumbens (NAc) is an area within the dopamine system implicated for SI (Manduca et al., 2016), and drug reward (Peoples and West, 1996). There is evidence that NAc MSNs are implicated in reward-associated cue presentation (Owesson-White et al., 2016) and cued reward seeking of alcohol (Valyear et al., 2020). NAc neurons also encode the lever press (Peoples and West, 1996; Owesson-White et al., 2016), reward approach (Valyear et al., 2020), and reward consumption (Nicola et al., 2004; Stamos, 2019). The NAc is composed of different types of cells; the majority medium spiny neurons (MSNs) (Kupchik and Kalivas, 2017) with the remainder primarily composed of other cells such as fast spiking interneurons (FSIs) (Schall et al., 2021). Some in vivo recording methods, such as electrophysiology, distinguish differential cell types by way of differential electrical patterns (Schall et al., 2021), including using waveform patterns to differentiate MSNs from FSIs (Berke et al., 2004; Morra et al., 2010; Sun and Laviolette, 2014). Many advancements in neuroscience were performed with in vivo electrophysiology. For example, MSNs contribute differentially - some increase in firing prior to a drug stimulus while others decrease (Peoples and West, 1996; Peoples et al., 1998). We now know that cellular subtypes of MSNs exist, and that NAc MSNs contain dopamine D1 or D2 receptor subtypes with distinct projections (Clark and White, 1987; Ikemoto et al., 1997; Kupchik et al., 2015). These subtypes are thought to contribute to processing motivation differentially. For example, NAc D1-MSNs encode reward (Tran et al., 2005; Lobo et al., 2010) while NAc D2-MSNs encode aversion (Danjo et al., 2014).
In addition, it has been shown that NAc D2-MSNs are involved in reward (Kupchik et al., 2015; Soares-Cunha et al., 2016; Cole et al., 2018) or a combinatory effect of D1- and D2MSNs encode reward motivated behavior (Ikemoto et al., 1997; Manduca et al., 2016).

In vivo electrophysiology recordings have limitations to readily separate D1- and D2- MSNs. Miniscopes, by contrast, provide a means to distinguish D1- and D2- MSNs. Researchers using miniscopes can take full advantage of modern advances in newly available transgenic animals (Pettibone et al., 2019; Heinsbroek et al., 2020; Table 1). By combining transgenic animals with Cre-dependent GECIs it is possible to target specific cell populations in the NAc and assess their contribution to SI and SUD (Zhang et al., 2019). With dual color miniscopes (Aharoni and Hoogland, 2019) being released, two cell populations can be imaged concurrently using GECIs with different excitation wavelengths (Park K. et al., 2021; Figure 1). This makes it possible to simultaneously dissect the contributions of multiple cell types from the same subject undergoing SI and drug SA. The amygdala, which is involved in SI (Bergan et al., 2014) and SUD (Holder et al., 2015) can be monitored with the same approach. GABAergic Amygdala neurons promote SI while glutamatergic neurons promoted selfgrooming (no SI behaviors) (Hong et al., 2014). This GABAergic and glutamatergic dichotomy can also be applied to ventral pallidum (VP) (Heinsbroek et al., 2020) which is also implicated in drug (Tang et al., 2005) and social reward (Young L.J. et al., 2001). Another example of differential subtype involvement is in 
TABLE 1 | Summary of miniscope benefits.

\begin{tabular}{|c|c|c|}
\hline Benefit & Examples & References \\
\hline \multirow{8}{*}{$\begin{array}{l}\text { 1. Identification of Cell } \\
\text { Types }\end{array}$} & GABAergic D1- expressing Neurons: & GABAergic D1- expressing neurons: \\
\hline & - Drd1-iCre & - Pettibone et al., 2019 \\
\hline & GABAergic D2- expressing Neurons: & GABAergic D2- expressing neurons: \\
\hline & - Adora2-iCre & - Pettibone et al., 2019 \\
\hline & Glutamatergic Neurons: & Glutamatergic Neurons: \\
\hline & - Vglut2-iCre & - Heinsbroek et al., 2020 \\
\hline & GABAergic Neurons: & GABAergic Neurons: \\
\hline & - Vgat-iCre & - Heinsbroek et al., 2020 \\
\hline \multirow{6}{*}{$\begin{array}{l}\text { 2. Longitudinal Imaging in } \\
\text { areas relevant to SI and } \\
\text { SUD and Manipulation of } \\
\text { Ensembles }\end{array}$} & Longitudinal Imaging of ensembles: & Longitudinal Imaging of ensembles \\
\hline & - Nucleus Accumbens & • Zhang et al., 2019 \\
\hline & - Prefrontal Cortex & • Liang et al., 2018; Kingsbury et al., 2019; Kingsbury et al., 2020 \\
\hline & • Hippocampus & • Jimenez et al., 2018 \\
\hline & Optogenetics Capable Miniscopes & Optogenetics Capable Miniscopes \\
\hline & & - Stamatakis et al., 2018; de Groot et al., 2020 \\
\hline \multirow{8}{*}{$\begin{array}{l}\text { 3. Behavioral Tools and } \\
\text { Analysis Software }\end{array}$} & Wire-free Miniscopes: & Wire-free Miniscopes: \\
\hline & & - Barbera et al., 2019; Shuman et al., 2020 \\
\hline & Motorized Commutator: & Motorized Commutator: \\
\hline & & - Coward and O'Boyle, 1979; Fee and Leonardo, 2001; Barbera et al., 2020 \\
\hline & GRIN lens coating to avert impact on & GRIN lens coating to avert impact on tissue health: \\
\hline & tissue health: & - Kyogoku et al., 1990; Yang et al., 2019 \\
\hline & Deep Learning Behavioral Analyses: & Deep Learning Behavioral Analysis: \\
\hline & & - Hong et al., 2015; Mathis et al., 2018; Mosser et al., 2021 \\
\hline
\end{tabular}

the prefrontal cortex (PFC) during social fear. Local microcircuits within PFC disinhibit other subtypes of inhibitory interneurons in order to gate social fear behavior (Xu et al., 2019). Using the miniscope to understand distinct contributions of cell subtypes such as these would be a major step forward in SI and SUD research (Table 1).

\section{Track Neural Activity Over Extended Periods of Time and Directly Manipulate Circuits}

The intricacies of circuitry involved in drug and social rewards are vast but critically important to study. It is also known that different rewards (such as food vs. drugs of abuse) may not necessarily be encoded by the same neurons (Martin-Fardon et al., 2018). Currently, we do not yet know how individual neurons or neural ensembles encode the choice between drugs vs. social reward (Venniro et al., 2019; Venniro and Shaham, 2020) or experience drug SA followed by social SA on different days. Do the same or distinct neurons and neural ensembles encode both drug and social SA? In the literature, animals can self-administer the opportunity to act aggressively to a smaller submissive animal (Golden et al., 2019) but how would these same neurons encode the opportunity to self-administer a more positively valanced SI (Venniro et al., 2018; Venniro and Shaham, 2020)? Furthermore, if a negative SI or drug situation is experienced (such as in the synchrony with pain or distress), how are neurons reorganized in response to these novel contexts? The miniscope, in combination with a GRIN lens, uses in vivo fluorescence imaging to track neuron activity over time during unrestrained behaviors, which provides an opportunity to study how the brain encodes drug SA and/or SI.
Miniscopes have been used to study neural activity in brain regions such as the NAc (Zhang et al., 2019) and PFC (Liang et al., 2018; Kingsbury et al., 2019, 2020; Table 1). These two regions are implicated in SI and SUD and thus are important targets of cellular resolution imaging (Peoples and West, 1996; Kalivas et al., 2005; Quintero, 2013; Manduca et al., 2016; Liang et al., 2018; Kingsbury et al., 2019, 2020; Xu et al., 2019). It is also important to consider imaging regions that project to the NAc and PFC. For example, the Hippocampus has been studied using miniscopes (Jimenez et al., 2018) SI memories are encoded in Hippocampus (Liu et al., 2019; Wu et al., 2020) and morphine withdrawal is associated with hyperactive glutamatergic uptake in the Hippocampus (Xu et al., 2003). The ventral tegmental area (VTA) is another region of interest involved in drug (Sun et al., 2005) and social reward (Hung et al., 2017).

Beyond the identification of cell type and cell "function," another benefit of the miniscope is the possibility for subsequent manipulation of the involved circuits at fine temporal resolutions using optogenetics, which can be used in addition to imaging (Stamatakis et al., 2018; de Groot et al., 2020; Figure 1; Table 1). The NAc and PFC circuit is strengthened during incubation of drug craving (Luís et al., 2017) and involved in social recognition (Park G. et al., 2021) which is impaired following social isolation. Through imaging, cellular ensemble activity can be correlated with behavior, but manipulation of ensembles is required to dissect functional roles. For example, would disrupting the PFC to NAc circuitry reduce incubation of drug craving? Similarly, would exciting this pathway overcome the impairment induced by social isolation? Neuroscientists can utilize tools such as total ablations of pathways (Kelly et al., 1975) but these are permanent changes that take place over days or weeks of time, lack temporal control, and affect other behaviors. Additionally, circuitry can be 
altered via chemogenic manipulations (Mahler and Aston-Jones, 2018), however, this approach has far less temporal control than optogenetics (taking time to onset and offset). These problems can be overcome with an optogenetics capable miniscope by e.g., using one channel to perform optogenetic activation or silencing of projection populations, or surrounding cells, while simultaneously imaging with the second channel (Stamatakis et al., 2018; de Groot et al., 2020; Figure 1; Table 1). In this scenario, optogenetic manipulations often consist of cellspecific viral transduction of cells with opsins that are then excited at wavelengths that can be separated from the excitation and emission wavelengths of the imaged fluorophore (Fenno et al., 2011). Some other technologies require a simultaneous implant of an optical fiber along with the recording device for optogenetic manipulations (Kravitz et al., 2013). This fibercoupled technique can be used in conjunction with miniscopes which may lack the second "built-in" optogenetic channel (Hong et al., 2014).

\section{Monitoring Unrestrained Animal Behavior That Allows Reliable Drug Self-Administration and Social Interaction}

One of the major advantages of miniscope imaging is the ability to study activity in awake, freely behaving animals. The miniscope can be mounted on the head of an animal with a light tether which allows the animal to perform behaviors naturally. Typical SI models require the need for active socialization (Rodriguiz et al., 2004; Manduca et al., 2016; Liang et al., 2018; Venniro et al., 2018, 2019; Golden et al., 2019; Venniro and Shaham, 2020), and the compact nature of the miniscope allows for the animal to freely explore it's environment. Using miniscopes, the animal is tethered to a freely rotating swivel which can be counterbalanced to reduce the overall weight on the animal (Zhang et al., 2019). This mechanism is similar to successful techniques used for other in vivo recordings such as electrophysiology (Fabbricatore et al., 2009). Wire-free miniscopes have also been developed (Barbera et al., 2019; Shuman et al., 2020) which can allow for study of SI in larger groups that would otherwise tangle and destroy wired systems. Moreover, advancements in behavior analysis (Hong et al., 2015; Mosser et al., 2021) enable neural activity imaged with miniscopes to be correlated with discrete phases of behavior. Studying the emergence of how specific subtypes of neurons encode various components of behavioral sequences of SI and SUD is critical to understanding overlapping neurobiology and to preventing drug relapse.

Given the ability of an animal to move freely, miniscopes allow for the implementation of more suitable behavioral paradigms that are relevant to SUD and SI. For example, SI can been modeled in many ways, including SI "choice" tasks (Venniro et al., 2018, 2019; Venniro and Shaham, 2020), sexual cue preference tasks (Bergan et al., 2014; Yao et al., 2017), and social fear (Toth and Neumann, 2013; Gutzeit et al., 2020). Similarly, SUD can be modeled in different ways; long-access SA (Roth and Carroll, 2004; Kitamura et al., 2006; Shepard et al., 2006; Rogers et al., 2008; Algallal et al., 2020; Klein et al., 2020) intermittent-access SA (Kawa et al., 2016; Nicolas et al., 2019; Algallal et al., 2020), and short-access SA (Roth and Carroll, 2004; Kitamura et al., 2006). Studying how neurons encode behaviors expressed in these different behavioral paradigms is critically important for increasing the translational validity of results to improving the human condition.

\section{DISCUSSION}

The use of SI in the treatment of SUD is a promising approach to help those suffering from SUD. Understanding the neurobiology of SI and SUD is crucial to understand why some people with SUD and access to treatment still suffer from drug relapse. In this review, we focused on three important aspects of studying the neurobiology of SI and SUD: identification of cell type and genetic influences, longitudinal imaging of individual neurons and neural ensembles with the potential for manipulation, and in vivo animal models. Dissecting the individual contributions of neural mechanisms requires temporally precise analysis. A limitation of calcium imaging is the performance of calcium sensors (Storace et al., 2015) where changes in calcium act a proxy of voltage fluctuations (Wachowiak et al., 2013). Furthermore, there are limitations of the imaging sensors used in miniscopes. However, genetically encoded voltage indicators (GEVIs) (Bando et al., 2019) and improved image sensors (Marshall et al., 2016; Juneau et al., 2018) offer a new horizon for increasing the temporal precision of miniscopes.

Through technological advancements in indicators, sensors, and imaging hardware, our understanding of the neurobiology underlying SI and SUD can be expanded. New analysis methods allow for the extraction of new information from imaging datasets, and miniscope imaging can be merged with deep learning software to extract cell type and circuit functions involved in SI- and SUD-related behaviors.

In summary, miniscopes allow for identification of distinct cell types. Miniscopes also allow for tracking the activity of neurons over extended periods of time and directly manipulating those microcircuits. Finally, miniscopes enable conditions to monitor unrestrained animal behavior that allows reliable SA. Together, miniscope imaging is a fantastic tool to identify underlying neurobiological functions of SI and SUD.

\section{AUTHOR CONTRIBUTIONS}

All authors prepared and edited the manuscript. NJB, KAW, and D-TL wrote the manuscript.

\section{FUNDING}

This research was supported by NIH NIDA IRP. NJB, CTW, and YZ were supported by Post-doctoral Fellowship from the Center on Compulsive Behaviors, National Institutes of Health. YL was supported by NIGMS COBRE 5P20GM121310-05. KAW was supported by NIDA IRP Scientific Director's Fellowship for Diversity in Research. 


\section{REFERENCES}

Aharoni, D., and Hoogland, T. M. (2019). Circuit investigations with opensource miniaturized microscopes: past, present and future. Front. Cell. Neurosci. 13:141. doi: 10.3389/fncel.2019.00141

Akerboom, J., Chen, T. W., Wardill, T. J., Tian, L., Marvin, J. S., Mutlu, S., et al. (2012). Optimization of a GCaMP calcium indicator for neural activity imaging. J. Neurosci. 32, 13819-13840. doi: 10.1523/JNEUROSCI.2601-12.2012

Algallal, H., Allain, F., Ndiaye, N. A., and Samaha, A. N. (2020). Sex differences in cocaine self-administration behaviour under long access versus intermittent access conditions. Addict. Biol. 25:e12809. doi: 10.1111/adb.12809

Bando, Y., Sakamoto, M., Kim, S., Ayzenshtat, I., and Yuste, R. (2019). Comparative evaluation of genetically encoded voltage indicators. Cell Rep. 26, 802.e4813.e4. doi: 10.1016/j.celrep.2018.12.088

Barbera, G., Liang, B., Zhang, L., Gerfen, C. R., Culurciello, E., Chen, R., et al. (2016). Spatially compact neural clusters in the dorsal striatum encode locomotion relevant information. Neuron 92, 202-213. doi: 10.1016/j.neuron. 2016.08.037

Barbera, G., Liang, B., Zhang, L., Li, Y., and Lin, D.-T. (2019). A wireless miniScope for deep brain imaging in freely moving mice. J. Neurosci. Methods 323, 56-60. doi: 10.1016/j.jneumeth.2019.05.008

Barbera, G., Zhang, Y., Werner, C., Liang, B., Li, Y., and Lin, D.-T. (2020). An open source motorized swivel for in vivo neural and behavioral recordings. Methods $X$ 7:101167. doi: 10.1016/j.mex.2020.101167

Bergan, J. F., Ben-Shaul, Y., and Dulac, C. (2014). Sex-specific processing of social cues in the medial amygdala. eLife 3:e02743. doi: 10.7554/eLife.02743.018

Berke, J. D., Okatan, M., Skurski, J., and Eichenbaum, H. B. (2004). Oscillatory entrainment of striatal neurons in freely moving rats. Neuron 43, 883-896. doi: 10.1016/j.neuron.2004.08.035

Bollimunta, A., Santacruz, S. R., Eaton, R. W., Xu, P. S., Morrison, J. H., Moxon, K. A., et al. (2021). Head-mounted microendoscopic calcium imaging in dorsal premotor cortex of behaving rhesus macaque. Cell Rep. 35:109239. doi: 10.1016/ j.celrep.2021.109239

Cai, D. J., Aharoni, D., Shuman, T., Shobe, J., Biane, J., Song, W., et al. (2016) A shared neural ensemble links distinct contextual memories encoded close in time. Nature 534, 115-118. doi: 10.1038/nature 17955

Chen, K. S., Xu, M., Zhang, Z., Chang, W. C., Gaj, T., Schaffer, D. V., et al. (2018). A hypothalamic switch for REM and Non-REM sleep. Neuron 97, 1168.e4-1176.e4. doi: 10.1016/j.neuron.2018.02.005

Chen, T. W., Wardill, T. J., Sun, Y., Pulver, S. R., Renninger, S. L., Baohan, A., et al. (2013). Ultrasensitive fluorescent proteins for imaging neuronal activity. Nature 499, 295-300. doi: 10.1038/nature12354

Clark, D., and White, F. J. (1987). D1 dopamine receptor-the search for a function: a critical evaluation of the D1/D2 dopamine receptor classification and its functional implications. Synapse 1, 347-388. doi: 10.1002/syn.8900 10408

Cole, S. L., Robinson, M. J., and Berridge, K. C. (2018). Optogenetic self-stimulation in the nucleus accumbens: D1 reward versus D2 ambivalence. PLoS One 13:e0207694. doi: 10.1371/journal.pone.0207694

Council, N. R. (2010). Guide for The Care and Use of Laboratory Animals. Washington, DC: National Academies Press.

Coward, R., and O'Boyle, D. J. (1979). Inexpensive 10-channel commutator for electrophysiological recording from behaving animals. Med. Biol. Eng. Comput. 17, 275-276. doi: 10.1007/BF02440942

Danjo, T., Yoshimi, K., Funabiki, K., Yawata, S., and Nakanishi, S. (2014). Aversive behavior induced by optogenetic inactivation of ventral tegmental area dopamine neurons is mediated by dopamine D2 receptors in the nucleus accumbens. Proc. Natl. Acad. Sci. U.S.A. 111, 6455-6460. doi: 10.1073/pnas. 1404323111

de Groot, A., Van Den Boom, B. J., Van Genderen, R. M., Coppens, J., Van Veldhuijzen, J., Bos, J., et al. (2020). NINscope, a versatile miniscope for multi-region circuit investigations. eLife 9:e49987. doi: 10.7554/eLife. 49987

Dishion, T. J., and Stormshak, E. A. (2007). Intervening in Children's Lives: An Ecological, Family-Centered Approach to Mental Health Care. Washington, DC: American Psychological Association. doi: 10.1037/11485-000

Fabbricatore, A. T., Ghitza, U. E., Prokopenko, V. F., and West, M. O. (2009). Electrophysiological evidence of mediolateral functional dichotomy in the rat accumbens during cocaine self-administration: tonic firing patterns. Eur. J. Neurosci. 30, 2387-2400. doi: 10.1111/j.1460-9568.2009.07033.x

Fee, M. S., and Leonardo, A. (2001). Miniature motorized microdrive and commutator system for chronic neural recording in small animals. J. Neurosci. Methods 112, 83-94. doi: 10.1016/S0165-0270(01)00426-5

Fenno, L., Yizhar, O., and Deisseroth, K. (2011). The development and application of optogenetics. Annu. Rev. Neurosci. 34, 389-412. doi: 10.1146/annurevneuro-061010-113817

Flagel, S. B., Watson, S. J., Akil, H., and Robinson, T. E. (2008). Individual differences in the attribution of incentive salience to a reward-related cue influence on cocaine sensitization. Behav. Brain Res. 186, 48-56. doi: 10.1016/j. bbr.2007.07.022

Förster, D., Kramer, A., Baier, H., and Kubo, F. (2018). Optogenetic precision toolkit to reveal form, function and connectivity of single neurons. Methods 150, 42-48. doi: 10.1016/j.ymeth.2018.08.012

Gerfen, C. R., Paletzki, R., and Heintz, N. (2013). GENSAT BAC cre-recombinase driver lines to study the functional organization of cerebral cortical and basal ganglia circuits. Neuron 80, 1368-1383. doi: 10.1016/j.neuron.2013. 10.016

Ghosh, K. K., Burns, L. D., Cocker, E. D., Nimmerjahn, A., Ziv, Y., Gamal, A. E., et al. (2011). Miniaturized integration of a fluorescence microscope. Nat. Methods 8, 871-878. doi: 10.1038/nmeth.1694

Golden, S. A., Jin, M., Heins, C., Venniro, M., Michaelides, M., and Shaham, Y. (2019). Nucleus accumbens Drd1-expressing neurons control aggression selfadministration and aggression seeking in mice. J. Neurosci. 39, 2482-2496. doi: 10.1523/JNEUROSCI.2409-18.2019

Gutzeit, V. A., Ahuna, K., Santos, T. L., Cunningham, A. M., Rooney, M. S., Zamora, A. M., et al. (2020). Optogenetic reactivation of prefrontal social neural ensembles mimics social buffering of fear. Neuropsychopharmacology 45, 1068-1077. doi: 10.1038/s41386-020-0631-1

Hayashi, Y., Kobayakawa, K., and Kobayakawa, R. (2021). Large-scale calcium imaging with a head-mount axial scanning 3D fluorescence microscope. bioRxiv [Preprint]. doi: 10.1101/2021.01.20.427512v1

Heinsbroek, J. A., Bobadilla, A.-C., Dereschewitz, E., Assali, A., Chalhoub, R. M., Cowan, C. W., et al. (2020). Opposing regulation of cocaine seeking by glutamate and GABA neurons in the ventral pallidum. Cell Rep. 30, 2018.e32027.e3. doi: 10.1016/j.celrep.2020.01.023

Heinsbroek, J. A., Neuhofer, D. N., Griffin, W. C. III, Siegel, G. S., Bobadilla, A. C., Kupchik, Y. M., et al. (2017). Loss of plasticity in the D2-accumbens pallidal pathway promotes cocaine seeking. J. Neurosci. 37, 757-767. doi: 10.1523/ JNEUROSCI.2659-16.2016

Holder, M. K., Veichweg, S. S., and Mong, J. A. (2015). Methamphetamineenhanced female sexual motivation is dependent on dopamine and progesterone signaling in the medial amygdala. Horm. Behav. 67, 1-11. doi: 10.1016/j.yhbeh.2014.10.004

Hong, W., Kennedy, A., Burgos-Artizzu, X. P., Zelikowsky, M., Navonne, S. G., Perona, P., et al. (2015). Automated measurement of mouse social behaviors using depth sensing, video tracking, and machine learning. Proc. Natl. Acad. Sci. U.S.A. 112, E5351-E5360. doi: 10.1073/pnas.1515982112

Hong, W., Kim, D.-W., and Anderson, D. J. (2014). Antagonistic control of social versus repetitive self-grooming behaviors by separable amygdala neuronal subsets. Cell 158, 1348-1361. doi: 10.1016/j.cell.2014.07.049

Hung, L. W., Neuner, S., Polepalli, J. S., Beier, K. T., Wright, M., Walsh, J. J., et al. (2017). Gating of social reward by oxytocin in the ventral tegmental area. Science 357, 1406-1411. doi: 10.1126/science.aan4994

Hunt, G. M., and Azrin, N. H. (1973). A community-reinforcement approach to alcoholism. Behav. Res. Ther. 11, 91-104. doi: 10.1016/0005-7967(73) 90072-7

Ikemoto, S., Glazier, B. S., Murphy, J. M., and Mcbride, W. J. (1997). Role of dopamine D1 and D2 receptors in the nucleus accumbens in mediating reward. J. Neurosci. 17, 8580-8587. doi: 10.1523/JNEUROSCI.17-21-08580.1997

Jacob, A. D., Ramsaran, A. I., Mocle, A. J., Tran, L. M., Yan, C., Frankland, P. W., et al. (2018). A compact head-mounted endoscope for in vivo calcium imaging in freely behaving mice. Curr. Protoc. Neurosci. 84:e51. doi: 10.1002/ cpns.51

Jimenez, J. C., Su, K., Goldberg, A. R., Luna, V. M., Biane, J. S., Ordek, G., et al. (2018). Anxiety cells in a hippocampal-hypothalamic circuit. Neuron 97, 670.e6-683.e6. doi: 10.1016/j.neuron.2018.01.016 
Juneau, J., Duret, G., Robinson, J., and Kemere, C. (2018). "Enhanced image sensor module for head-mounted microscopes," in Proceedings of the 2018 40th Annual International Conference of the IEEE Engineering in Medicine and Biology Society (EMBC), (Piscataway, NJ: IEEE), 826-829. doi: 10.1109/EMBC. 2018.8512387

Kalivas, P., Volkow, N., and Seamans, J. (2005). Unmanageable motivation in addiction: a pathology in prefrontal-accumbens glutamate transmission. Neuron 45, 647-650. doi: 10.1016/j.neuron.2005.02.005

Kawa, A. B., Bentzley, B. S., and Robinson, T. E. (2016). Less is more: prolonged intermittent access cocaine self-administration produces incentivesensitization and addiction-like behavior. Psychopharmacology 233, 3587-3602. doi: 10.1007/s00213-016-4393-8

Kawachi, I., and Berkman, L. F. (2001). Social ties and mental health. J. Urban Health 78, 458-467. doi: g/10.1093/jurban/78.3.458

Kelly, P. H., Seviour, P. W., and Iversen, S. D. (1975). Amphetamine and apomorphine responses in the rat following 6-OHDA lesions of the nucleus accumbens septi and corpus striatum. Brain Res. 94, 507-522. doi: 10.1016/ 0006-8993(75)90233-4

Kennedy, A. P., Epstein, D. H., Phillips, K. A., and Preston, K. L. (2013). Sex differences in cocaine/heroin users: drug-use triggers and craving in daily life. Drug Alcohol Depend. 132, 29-37. doi: 10.1016/j.drugalcdep.2012.12.025

Kingsbury, L., Huang, S., Raam, T., Letizia, S. Y., Wei, D., Hu, R. K., et al. (2020). Cortical representations of conspecific sex shape social behavior. Neuron 107, 941.e7-953.e7. doi: 10.1016/j.neuron.2020.06.020

Kingsbury, L., Huang, S., Wang, J., Gu, K., Golshani, P., Wu, Y. E., et al. (2019). Correlated neural activity and encoding of behavior across brains of socially interacting animals. Cell 178, 429.e16-446.e16. doi: 10.1016/j.cell.2019. 05.022

Kitamura, O., Wee, S., Specio, S. E., Koob, G. F., and Pulvirenti, L. (2006). Escalation of methamphetamine self-administration in rats: a dose-effect function. Psychopharmacology 186, 48-53. doi: 10.1007/s00213-006-0353-z

Klaus, A., Martins, G. J., Paixao, V. B., Zhou, P., Paninski, L., and Costa, R. M. (2017). The spatiotemporal organization of the striatum encodes action space. Neuron 96:949. doi: 10.1016/j.neuron.2017.08.015

Klein, S. D., Beacher, N. J., Kulik, J. M., Estrin, D. J., Pawlak, A. P., and West, M. O. (2020). Emergence of negative affect as motivation for drug taking in rats chronically self-administering cocaine. Psychopharmacology 237, 1407-1420. doi: 10.1007/s00213-020-05468-1

Kondabolu, K., Kowalski, M. M., Roberts, E. A., and Han, X. (2015). Optogenetics and deep brain stimulation neurotechnologies. Handb. Exp. Pharmacol. 228, 441-450. doi: 10.1007/978-3-319-16522-6_15

Kravitz, A. V., Owen, S. F., and Kreitzer, A. C. (2013). Optogenetic identification of striatal projection neuron subtypes during in vivo recordings. Brain Res. 1511, 21-32. doi: 10.1016/j.brainres.2012.11.018

Kuiper, S., and Hendriks, B. (2004). Variable-focus liquid lens for miniature cameras. Appl. Phys. Lett. 85, 1128-1130. doi: 10.1063/1.1779954

Kupchik, Y. M., Brown, R. M., Heinsbroek, J. A., Lobo, M. K., Schwartz, D. J., and Kalivas, P. W. (2015). Coding the direct/indirect pathways by D1 and D2 receptors is not valid for accumbens projections. Nat. Neurosci. 18, 1230-1232. doi: $10.1038 / \mathrm{nn} .4068$

Kupchik, Y. M., and Kalivas, P. W. (2017). The direct and indirect pathways of the nucleus accumbens are not what you think. Neuropsychopharmacology 42:369. doi: $10.1038 /$ npp. 2016.160

Kyogoku, T., Suzuki, T., and Mino, M. (1990). Ion beam assisted deposition of a thin film coating on a gradient-index lens array. Appl. Opt. 29, 4071-4076. doi: 10.1364/AO.29.004071

Laing, B. T., Siemian, J. N., Sarsfield, S., and Aponte, Y. (2021). Fluorescence microendoscopy for in vivo deep-brain imaging of neuronal circuits. J. Neurosci. Methods 348:109015. doi: 10.1016/j.jneumeth.2020.109015

Leiner, D. C., and Prescott, R. (1983). Correction of chromatic aberrations in GRIN endoscopes. Appl. Opt. 22, 383-386. doi: 10.1364/AO.22.000383

Leman, D., Chen, I., Yen, W., Cruz-Martin, A., Perkins, N., Liberti, W., et al. (2018). An expanded Open-Source Toolbox for Widefield Calcium Imaging in Freely Behaving Animals. Program No. 338.20. 2018 Neuroscience Meeting Planner. San Diego, CA: Society for Neuroscience.

Levene, M. J., Dombeck, D. A., Kasischke, K. A., Molloy, R. P., and Webb, W. W. (2004). In vivo multiphoton microscopy of deep brain tissue. J. Neurophysiol. 91, 1908-1912. doi: 10.1152/jn.01007.2003
Liang, B., Zhang, L., Barbera, G., Fang, W., Zhang, J., Chen, X., et al. (2018). Distinct and dynamic ON and OFF neural ensembles in the prefrontal cortex code social exploration. Neuron 100, 700.e4-714.e4. doi: 10.1016/j.neuron.2018. 08.043

Liang, B., Zhang, L., Moffitt, C., Li, Y., and Lin, D.-T. (2019). An open-source automated surgical instrument for microendoscope implantation. J. Neurosci. Methods 311, 83-88. doi: 10.1016/j.jneumeth.2018.10.013

Liu, X.-D., Ai, P.-H., Zhu, X.-N., Pan, Y.-B., Halford, M. M., Henkemeyer, M., et al. (2019). Hippocampal Lnx1-NMDAR multiprotein complex mediates initial social memory. Mol. Psychiatry [Epub ahead of print]. doi: 10.1038/s41380019-0606-y

Lobo, M. K., Covington, H. E., Chaudhury, D., Friedman, A. K., Sun, H., DamezWerno, D., et al. (2010). Cell type-specific loss of BDNF signaling mimics optogenetic control of cocaine reward. Science 330, 385-390. doi: 10.1126/ science. 1188472

Luís, C., Cannella, N., Spanagel, R., and Köhr, G. (2017). Persistent strengthening of the prefrontal cortex-nucleus accumbens pathway during incubation of cocaine-seeking behavior. Neurobiol. Learn. Mem. 138, 281-290. doi: 10.1016/ j.nlm.2016.10.003

Mahler, S. V., and Aston-Jones, G. (2018). CNO evil? Considerations for the use of DREADDs in behavioral neuroscience. Neuropsychopharmacology 43, 934-936. doi: 10.1038/npp.2017.299

Manduca, A., Servadio, M., Damsteegt, R., Campolongo, P., Vanderschuren, L. J., and Trezza, V. (2016). Dopaminergic neurotransmission in the nucleus accumbens modulates social play behavior in rats. Neuropsychopharmacology 41, 2215-2223. doi: 10.1038/npp.2016.22

Markowitz, J. E., Liberti, W. A. III, Guitchounts, G., Velho, T., Lois, C., and Gardner, T. J. (2015). Mesoscopic patterns of neural activity support songbird cortical sequences. PLoS Biol. 13:e1002158. doi: 10.1371/journal.pbio. 1002158

Marshall, J. D., Li, J. Z., Zhang, Y., Gong, Y., St-Pierre, F., Lin, M. Z., et al. (2016) Cell-type-specific optical recording of membrane voltage dynamics in freely moving mice. Cell 167, 1650.e15-1662.e15. doi: 10.1016/j.cell.2016.11.021

Martín, R., Bajo-Grañeras, R., Moratalla, R., Perea, G., and Araque, A. (2015). Circuit-specific signaling in astrocyte-neuron networks in basal ganglia pathways. Science 349, 730-734. doi:/10.1126/science.aaa7945

Martin-Fardon, R., Cauvi, G., Kerr, T. M., and Weiss, F. (2018). Differential role of hypothalamic orexin/hypocretin neurons in reward seeking motivated by cocaine versus palatable food. Addict. Biol. 23, 6-15. doi: 10.1111/adb.12441

Mathis, A., Mamidanna, P., Cury, K. M., Abe, T., Murthy, V. N., Mathis, M. W., et al. (2018). DeepLabCut: markerless pose estimation of user-defined body parts with deep learning. Nat. Neurosci. 21, 1281-1289. doi: 10.1038/s41593018-0209-y

Morra, J. T., Glick, S. D., and Cheer, J. F. (2010). Neural encoding of psychomotor activation in the nucleus accumbens core, but not the shell, requires cannabinoid receptor signaling. J. Neurosci. 30, 5102-5107. doi: 10 . 1523/JNEUROSCI.5335-09.2010

Mosser, C. A., Haqqee, Z., Nieto-Posadas, A., Murai, K. K., Stifani, S., Williams, S., et al. (2021). The McGill-Mouse-Miniscope platform: a standardized approach for high-throughput imaging of neuronal dynamics during behavior. Genes Brain Behav. 20:e12686. doi: 10.1111/gbb.12686

Nakai, J., Ohkura, M., and Imoto, K. (2001). A high signal-to-noise $\mathrm{Ca}(2+)$ probe composed of a single green fluorescent protein. Nat. Biotechnol. 19, 137-141. doi: $10.1038 / 84397$

Nath, T., Mathis, A., Chen, A. C., Patel, A., Bethge, M., and Mathis, M. W. (2019). Using DeepLabCut for 3D markerless pose estimation across species and behaviors. Nat. Protoc. 14, 2152-2176. doi: 10.1038/s41596-019-0176-0

Natsubori, A., Tsutsui-Kimura, I., Nishida, H., Bouchekioua, Y., Sekiya, H., Uchigashima, M., et al. (2017). Ventrolateral striatal medium spiny neurons positively regulate food-incentive, goal-directed behavior independently of D1 and D2 selectivity. J. Neurosci. 37, 2723-2733. doi: 10.1523/JNEUROSCI.337716.2017

Nestler, E. J. (2002). From neurobiology to treatment: progress against addiction. Nat. Neurosci. 5, 1076-1079. doi: 10.1038/nn945

Nicola, S. M., Yun, I. A., Wakabayashi, K. T., and Fields, H. L. (2004). Firing of nucleus accumbens neurons during the consummatory phase of a discriminative stimulus task depends on previous reward predictive cues. J. Neurophysiol. 91, 1866-1882. doi: 10.1152/jn.00658.2003 
Nicolas, C., Russell, T. I., Pierce, A. F., Maldera, S., Holley, A., You, Z.-B., et al. (2019). Incubation of cocaine craving after intermittent-access selfadministration: sex differences and estrous cycle. Biol. Psychiatry 85, 915-924. doi: 10.1016/j.biopsych.2019.01.015

Okuyama, T., Kitamura, T., Roy, D. S., Itohara, S., and Tonegawa, S. (2016). Ventral CA1 neurons store social memory. Science 353, 1536-1541. doi: 10. 1126/science.aaf7003

Owesson-White, C., Belle, A. M., Herr, N. R., Peele, J. L., Gowrishankar, P., Carelli, R. M., et al. (2016). Cue-evoked dopamine release rapidly modulates D2 neurons in the nucleus accumbens during motivated behavior. J. Neurosci. 36, 6011-6021. doi: 10.1523/JNEUROSCI.0393-16.2016

Park, G., Ryu, C., Kim, S., Jeong, S. J., Koo, J. W., Lee, Y.-S., et al. (2021). Social isolation impairs the prefrontal-nucleus accumbens circuit subserving social recognition in mice. Cell Rep. 35:109104. doi: 10.1016/j.celrep.2021.109104

Park, K., Liyanage, A. C., Koretsky, A. P., Pan, Y., and Du, C. (2021). Optical imaging of stimulation-evoked cortical activity using GCaMP6f and jRGECO1a. Q. Imaging Med. Surg. 11:998. doi: 10.21037/qims-20-921

Parker, J. G., Marshall, J. D., Ahanonu, B., Wu, Y. W., Kim, T. H., Grewe, B. F., et al. (2018). Diametric neural ensemble dynamics in parkinsonian and dyskinetic states. Nature 557, 177-182. doi: 10.1038/s41586-018-0090-6

Peoples, L. L., Gee, F., Bibi, R., and West, M. O. (1998). Phasic firing time locked to cocaine self-infusion and locomotion: dissociable firing patterns of single nucleus accumbens neurons in the rat. J. Neurosci. 18, 7588-7598. doi: 10.1523/ JNEUROSCI.18-18-07588.1998

Peoples, L. L., and West, M. O. (1996). Phasic firing of single neurons in the rat nucleus accumbens correlated with the timing of intravenous cocaine selfadministration. J. Neurosci. 16, 3459-3473. doi: 10.1523/JNEUROSCI.16-1003459.1996

Pettibone, J. R., Yu, J. Y., Derman, R. C., Faust, T. W., Hughes, E. D., Filipiak, W. E., et al. (2019). Knock-in rat lines with cre recombinase at the dopamine D1 and adenosine 2a receptor loci. eNeuro 6:ENEURO.0163-19.2019. doi: 10.1523/ENEURO.0163-19.2019

Quintero, G. C. (2013). Role of nucleus accumbens glutamatergic plasticity in drug addiction. Neuropsychiatr. Dis. Treat. 9:1499. doi: 10.2147/NDT. S45963

Ren, H., and Wu, S.-T. (2007). Variable-focus liquid lens. Optics Express 15, 5931-5936. doi: 10.1364/OE.15.005931

Robinson, T. E., and Berridge, K. C. (1993). The neural basis of drug craving: an incentive-sensitization theory of addiction. Brain Res. Rev. 18, 247-291. doi: 10.1016/0165-0173(93)90013-P

Rodriguiz, R. M., Chu, R., Caron, M. G., and Wetsel, W. C. (2004). Aberrant responses in social interaction of dopamine transporter knockout mice. Behav. Brain Res. 148, 185-198. doi: 10.1016/S0166-4328(03)00187-6

Rogers, J., De Santis, S., and See, R. (2008). Extended methamphetamine selfadministration enhances reinstatement of drug seeking and impairs novel object recognition in rats. Psychopharmacology 199, 615-624. doi: 10.1007/ s00213-008-1187-7

Rose, T., Goltstein, P. M., Portugues, R., and Griesbeck, O. (2014). Putting a finishing touch on GECIs. Front. Mol. Neurosci. 7:88. doi: 10.3389/fnmol.2014. 00088

Roth, M. E., and Carroll, M. E. (2004). Sex differences in the escalation of intravenous cocaine intake following long-or short-access to cocaine selfadministration. Pharmacol. Biochem. Behav. 78, 199-207. doi: 10.1016/j.pbb. 2004.03.018

Schall, T. A., Wright, W. J., and Dong, Y. (2021). Nucleus accumbens fastspiking interneurons in motivational and addictive behaviors. Mol. Psychiatry 26, 234-246. doi: 10.1038/s41380-020-0683-y

Shepard, J. D., Chuang, D. T., Shaham, Y., and Morales, M. (2006). Effect of methamphetamine self-administration on tyrosine hydroxylase and dopamine transporter levels in mesolimbic and nigrostriatal dopamine pathways of the rat. Psychopharmacology 185, 505-513. doi: 10.1007/s00213-0060316-4

Shuman, T., Aharoni, D., Cai, D. J., Lee, C. R., Chavlis, S., Page-Harley, L., et al. (2020). Breakdown of spatial coding and interneuron synchronization in epileptic mice. Nat. Neurosci. 23, 229-238. doi: 10.1038/s41593-0190559-0

Soares-Cunha, C., Coimbra, B., David-Pereira, A., Borges, S., Pinto, L., Costa, P., et al. (2016). Activation of D2 dopamine receptor-expressing neurons in the nucleus accumbens increases motivation. Nat. Commun. 7, 1-11. doi: 10.1038/ ncomms 11829

Stamatakis, A. M., Schachter, M. J., Gulati, S., Zitelli, K. T., Malanowski, S., Tajik, A., et al. (2018). Simultaneous optogenetics and cellular resolution calcium imaging during active behavior using a miniaturized microscope. Front. Neurosci. 12:496. doi: 10.3389/fnins.2018.00496

Stamos, J. (2019). Accumbens Processing of a Food Associated Cue in a Rat Model of Binge Eating. New Brunswick, NJ: Rutgers University-School of Graduate Studies.

Storace, D. A., Braubach, O. R., Jin, L., Cohen, L. B., and Sung, U. (2015). Monitoring brain activity with protein voltage and calcium sensors. Sci. Rep. $5,1-15$.

Sun, N., and Laviolette, S. R. (2014). Dopamine receptor blockade modulates the rewarding and aversive properties of nicotine via dissociable neuronal activity patterns in the nucleus accumbens. Neuropsychopharmacology 39, 2799-2815.

Sun, W., Akins, C. K., Mattingly, A. E., and Rebec, G. V. (2005). Ionotropic glutamate receptors in the ventral tegmental area regulate cocaine-seeking behavior in rats. Neuropsychopharmacology 30, 2073-2081.

Tallini, Y. N., Ohkura, M., Choi, B. R., Ji, G., Imoto, K., Doran, R., et al. (2006). Imaging cellular signals in the heart in vivo: cardiac expression of the high-signal Ca2+ indicator GCaMP2. Proc. Natl. Acad. Sci. U.S.A. 103, 4753-4758.

Tang, X.-C., Mcfarland, K., Cagle, S., and Kalivas, P. W. (2005). Cocaine-induced reinstatement requires endogenous stimulation of $\mu$-opioid receptors in the ventral pallidum. J. Neurosci. 25, 4512-4520.

Tian, L., Hires, S. A., Mao, T., Huber, D., Chiappe, M. E., Chalasani, S. H., et al. (2009). Imaging neural activity in worms, flies and mice with improved GCaMP calcium indicators. Nat. Methods 6, 875-881.

Toth, I., and Neumann, I. D. (2013). Animal models of social avoidance and social fear. Cell Tissue Res. 354, 107-118.

Tran, A. H., Tamura, R., Uwano, T., Kobayashi, T., Katsuki, M., and Ono, T. (2005). Dopamine D1 receptors involved in locomotor activity and accumbens neural responses to prediction of reward associated with place. Proc. Natl. Acad. Sci. U.S.A. 102, 2117-2122.

Valyear, M. D., Glovaci, I., Zaari, A., Lahlou, S., Trujillo-Pisanty, I., Chapman, C. A., et al. (2020). Dissociable mesolimbic dopamine circuits control responding triggered by alcohol-predictive discrete cues and contexts. Nat. Commun. 11, $1-14$.

Venniro, M., Russell, T. I., Zhang, M., and Shaham, Y. (2019). Operant social reward decreases incubation of heroin craving in male and female rats. Biol. Psychiatry 86, 848-856.

Venniro, M., and Shaham, Y. (2020). An operant social self-administration and choice model in rats. Nat. Protoc. 15, 1542-1559.

Venniro, M., Zhang, M., Caprioli, D., Hoots, J. K., Golden, S. A., Heins, C., et al. (2018). Volitional social interaction prevents drug addiction in rat models. Nat. Neurosci. 21, 1520-1529.

Wachowiak, M., Economo, M. N., Díaz-Quesada, M., Brunert, D., Wesson, D. W., White, J. A., et al. (2013). Optical dissection of odor information processing in vivo using GCaMPs expressed in specified cell types of the olfactory bulb. J. Neurosci. 33, 5285-5300.

Werner, C. T., Williams, C. J., Fermelia, M. R., Lin, D.-T., and Li, Y. (2019). Circuit mechanisms of neurodegenerative diseases: a new frontier with miniature fluorescence microscopy. Front. Neurosci. 13:1174. doi: 10.3389/fnins.2019. 01174

Wu, X.-R., Zhang, Y., Liu, X.-D., Han, W.-B., Xu, N.-J., and Sun, S. (2020). EphB2 mediates social isolation-induced memory forgetting. Transl. Psychiatry 10, 1-12. doi: 10.1038/s41398-020-01051-6

Xu, H., Liu, L., Tian, Y., Wang, J., Li, J., Zheng, J., et al. (2019). A disinhibitory microcircuit mediates conditioned social fear in the prefrontal cortex. Neuron 102, 668.e5-682.e5. doi: 10.1016/j.neuron.2019.02.026

Xu, N.-J., Bao, L., Fan, H.-P., Bao, G.-B., Pu, L., Lu, Y.-J., et al. (2003). Morphine withdrawal increases glutamate uptake and surface expression of glutamate transporter GLT1 at hippocampal synapses. J. Neurosci. 23, 4775-4784. doi: 10.1523/JNEUROSCI.23-11-04775.2003

Yang, Y., Liu, N., He, Y., Liu, Y., Ge, L., Zou, L., et al. (2018). Improved calcium sensor GCaMP-X overcomes the calcium channel perturbations induced by the calmodulin in GCaMP. Nat. Commun. 9:1504. doi: 10.1038/s41467-01803719-6 
Yang, Y., Zhang, L., Wang, Z., Liang, B., Barbera, G., Moffitt, C., et al. (2019). A twostep GRIN lens coating for in vivo brain imaging. Neurosci. Bull. 35, 419-424. doi: 10.1007/s12264-019-00356-x

Yao, S., Bergan, J., Lanjuin, A., and Dulac, C. (2017). Oxytocin signaling in the medial amygdala is required for sex discrimination of social cues. eLife 6:e31373. doi: 10.7554/eLife.31373.019

Young, A. M., Boyd, C., and Hubbell, A. (2001). Social Isolation \& Sexual Abuse Among Women Who Smoke Crack. Thorofare, NJ: SLACK Incorporated.

Young, L. J., Lim, M. M., Gingrich, B., and Insel, T. R. (2001). Cellular mechanisms of social attachment. Horm. Behav. 40, 133-138. doi: 10.1006/hbeh.2001.1691

Zhang, L., Liang, B., Barbera, G., Hawes, S., Zhang, Y., Stump, K., et al. (2019). Miniscope GRIN lens system for calcium imaging of neuronal activity from deep brain structures in behaving animals. Curr. Protoc. Neurosci. 86:e56. doi: 10.1002/cpns.56

Zhang, Y., Rózsa, M., Bushey, D., Zheng, J., Reep, D., Broussard, G. J., et al. (2020). jGCaMP8 Fast Genetically Encoded Calcium Indicators. Ashburn, VA: Janelia Research Campus.
Conflict of Interest: The authors declare that the research was conducted in the absence of any commercial or financial relationships that could be construed as a potential conflict of interest.

Publisher's Note: All claims expressed in this article are solely those of the authors and do not necessarily represent those of their affiliated organizations, or those of the publisher, the editors and the reviewers. Any product that may be evaluated in this article, or claim that may be made by its manufacturer, is not guaranteed or endorsed by the publisher.

Copyright (c) 2021 Beacher, Washington, Werner, Zhang, Barbera, Li and Lin. This is an open-access article distributed under the terms of the Creative Commons Attribution License (CC BY). The use, distribution or reproduction in other forums is permitted, provided the original author(s) and the copyright owner(s) are credited and that the original publication in this journal is cited, in accordance with accepted academic practice. No use, distribution or reproduction is permitted which does not comply with these terms. 